\title{
The COVID-19: Yet another Viral Spill-Over of Unexpected Consequences
}

\author{
Samina Naz Mukry* \\ Department of Post Graduate Studies \& Research, National Institute of Blood Disease \& Bone Marrow Transplantation, Karachi, Pakistan.
}

The human coronaviruses $(\mathrm{CoV})$ are the causative agent of respiratory illness in human especially during winter and fall. They were first identified in 1960's. The four corona strains i.e. NL63, 229E, HKU1 and OC63 accounts for about $30 \%$ of the annual common cold incidences ranging from mild to moderate illness in human worldwide. These are the largest RNA viruses from the sub-family Orthocoronavirinae of family Coronaviridae. Interestingly, the crown like spikes on their surface make them unique. So far four different groups of coronaviruses have been identified namely: alpha-, beta-, delta-, gamma- coronaviruses [1]. Beside the reported human-only beta coronaviruses HKU1 and OC63; lethal outbreaks of three other beta corona viruses i.e. Severe Acute Respiratory Syndrome (SARS), Middle East Respiratory Syndrome (MERS) and SARS-CoV2 - viruses were documented. The later three viral strains were confirmed as evolved viruses from animal origin. The genetic diversity of these viruses is sought to be facilitated by recombination and mutational events within the intermediate host predominantly a mammal.

The world witnessed the first major epidemic of beta coronavirus infection caused by virus of animal origin from Guangdong, China at the beginning of the ongoing century in $2002 / 2003$. The mortality rate due to SARS turned out to be around $10 \%$ with total confirmed cases of 8096 worldwide. The bats were identified as the reservoir with infected civets as primary host. More specifically, the common symptoms included fever, headache, body ache, feeling of abdominal discomfort etc. After 2-7days of infection; patient generally presents with dry cough and pneumonia. Furthermore, the mode of transmission was direct or close human to human contact. The source control or discouraging contact with wild civets proved to be the best preventive measure in controlling this outbreak [2].

As a consequence of breach of specie barrier; another specie jump of zoonotic viral respiratory infection; MERS was identified in middle east in 2012/2013. Similar to SARS the bats infected the intermediate mammalian host i.e. camel in this case. To date 858 deaths have been reported worldwide due to MERS as of December 2019 [3].

The latest outbreak (now a pandemic) of the novel coronavirus named Corona Virus Disease (Covid-19) by WHO was

*Address correspondence to this author at the Department of Post Graduate Studies \& Research, National Institute of Blood Disease \& Bone Marrow Transplantation, Karachi, Pakistan. E-mail: smukry@gmail.com reported from Wuhan, China as an outbreak of pneumonia of unknown origin in late December, 2019 [4]. Initially, the source was identified as live seafood bought from seafood market. The market was later on decontaminated and sealed by Chinese authorities to prevent further transmission. Investigations of infected family members returning from Wuhan revealed that there might be perfectly healthy asymptomatic carriers capable of transmitting virus to other human through close contact [5].

Consequently, it has been assumed that with more than $70 \%$ sequence similarity with SARS virus and other SARS like virus of bats that the reservoirs could be bats with minks and mammals as intermediate hosts [6]. But the exact origin of virus has not been accurately confirmed and still remained unknown. In January 2020 the Chinese center of disease control CDC has fully sequenced and shared the genome sequence of this virus confirming its novelty. This virus has sequence similarity with spikes of SARS virus and therefore it has been found to cause lower respiratory discomfort, pneumonia and sudden deaths. The cause of pneumonia may be due to binding of virus to via receptor binding $\mathrm{S}$ protein to angiotensin-converting enzyme 2 (ACE2) receptors in lungs [2]. Much progress has been made in understanding SARS CoV2 but the pathogenesis is still unclear. The available data supports that the virus is capable of producing an excessive immune reaction or cytokine storm causing extensive tissue damage of organs expressing ACE2 receptors in the host [5, 7].

The variability in disease pattern ranging from mild respiratory illness to severe pneumonia was initially reported to be age dependent with a high death rate in immune compromised elderly adults having comorbidities such as diabetes and heart problems. Evident unfavorable fatal outcomes due to COVID-19 infection in individuals with weakened immune system and in frontline workers owing to excessive virus exposure changed this perception. The average virus incubation period is 2-14 days with fever, cough, body pain, fatigue, abdominal distress and difficulty in breathing as characteristic symptoms of this infection. The abnormal laboratory findings include thrombocytopenia, leucopenia, increased CRP, altered liver and renal function tests and pulmonary ground glass like opacities [8]. As of $30^{\text {th }}$ March 2020 about 693282 laboratory confirmed cases of the COVID-19 has so far been reported globally with about 33108 deaths. Despite an increased rate of transmission and high number of deaths the 
rate of mortality for COVID-19 is low (4.77\%) compared to SARS and MERS [8]. In this recent outbreak asymptomatic carrier may act as reservoir and virus transmitted from healthy human to others may be variants due to possible transformation events within host as was observed in SARS [9]. This is one of the reason why the international bodies such as CDC and WHO has emphasized on investigating suspected patients with COVID and flu like respiratory viral infection (possibly due to other coronaviruses). Certain interim standard guideline to prevent COVID has been proposed by CDC with an investigation criterion for expected patients/person under investigation (PUI). The PUI is based on clinical features including fever, cough and shortness of breath as well as epidemiological risk factors such as possible close contact with suspected or confirmed COVID-19 cases, history of visit to either China or Wuhan or any foreign country with outbreak within past 14 days. A quarantine of 14 days of even asymptomatic individuals returning or coming from China or foreign countries has been suggested as a measure to limit cross border transmission of this virus. As per international risk assessment there was a very high risk of COVID-19 in China while high risk level has been assigned to the rest of the world $[6,8,10]$. Household and health services based surveillance has been encouraged and an anonymous platform of data sharing has been offered to encourage data sharing from clinical as well as epidemiological studies.

Moreover, compliance with standard, contact and airborne precaution along with eye protection may minimize the viral transmission through uncleaned hands, droplets in air and contaminated surfaces at hospitals and care homes. A supervised or buddy system donning and doffing of PPE is recommended to avoid SARS-CoV2 infection in healthcare workers $(0.3 \%$ mortality rate) $[11,12]$. A mandatory fit test of mask due to small sized droplet $(5 \mu \mathrm{m})$ capable of travelling up to $4.5 \mathrm{~m}$ and persistence in air for 3 hours is recommended for staff including those not in direct contacts with patients [13]. The possible persistence of virus on inanimate objects of steel (48h), copper (4h), plastic (72h) or cardboard (24h) others for up to 9 days also warrants caution [14]. The environmental decontamination with appropriate disinfectant such as $0.1 \%$ hypochlorite may be efficient for prevention of spread and containment of this incurable infectious threat [13]. Despite multiple trials no confirmed treatment is available. To-date no vaccine has been developed and exact consequences of this infection at global scale especially in resource limited countries cannot be precisely forecasted hence precautions for prevention has been the best suggested strategy so far.

Furthermore, the worldwide regional and international socioeconomic impacts of quarantine are yet to be discovered. Amidst uncertainties commendable resilient actions by WHO and CDC such as precise, logical data sharing, timely global risk assessment and strategic plan for bio-containment and infection prevention/control should be appreciated. As an additional solution the 'One health' program should be promoted to gain further insight into probable zoonotic viral infections in future.

\section{CONFLICT OF INTEREST}

Declared none.

\section{ACKNOWLEDGEMENTS}

Declared none.

\section{REFERENCES}

[1] Fehr AR, Perlman S. Coronaviruses: An overview of their replication and pathogenesis. Methods Mol Biol (Clifton, NJ) 2015; 1282: 1-23.

DOI: $10.1007 / 978-1-4939-2438-7 \_1$

[2] Li F, Li W, Farzan M, Harrison SC. Structure of SARS coronavirus spike receptor-binding domain complexed with receptor. Science (New York, NY) 2005; 309(5742): 1864-8. DOI: 10.1126/science.1116480

[3] WHO. Statement regarding cluster of pneumonia cases in Wuhan, China. 2020; (cited 2020, 9 January). Available from: www.who.int.

[4] Transmission of Novel Coronavirus (2019-nCoV) CDC. 2020; Available at https://www.who.int/docs/def a u l t - s our ce / c oronaviruse/s i t u a tion-reports/20200211-sitrep-22-ncov

[5] Chan JF-W, Yuan S, Kok K-H, et al. A familial cluster of pneumonia associated with the 2019 novel coronavirus indicating person-to-person transmission: a study of a family cluster. Lancet 2020; 395(10223): 514-23. DOI: $10.1016 / \mathrm{S} 0140-6736(20) 30154-9$

[6] Zhu N, Zhang D, Wang W, et al. A novel coronavirus from patients with pneumonia in China, 2019. New Engl J Med 2020; 382(8): 727-33.

DOI: 10.1056/NEJMoa2001017

[7] Fung S-Y, Yuen K-S, Ye Z-W, Chan C-P, Jin D-Y. A tug-of-war between severe acute respiratory syndrome coronavirus 2 and host antiviral defence: Lessons from other pathogenic viruses. Emerg Microbes Infect 2020; 9(1): 558-70. DOI: 10.1080/22221751.2020.1736644

[8] Coronavirus Disease 2019 (COVID-19) Situation Report - 70. 2020; Availabe at: https://www.who.int/docs/default-source/coronaviruse/situation-reports/20200330-sitrep-70-covid-19.pdf?sfvrsn=7 e0fe3f8 4

[9] Huang C, Wang Y, Li X, et al. Clinical features of patients infected with 2019 novel coronavirus in Wuhan, China. Lancet 2020; 395(10223): 497-506. 
DOI: 10.1016/S0140-6736(20)30183-5

[10] Li Q, Guan X, Wu P, et al. Early transmission dynamics in Wuhan, China, of novel coronavirus-infected pneumonia. New Engl J Med 2020; 382(13): 1199-207. DOI: 10.1056/NEJMoa2001316

[11] Bricknell M, Hodgetts T, Beaton K, McCourt A. Operation GRITROCK: The defence medical services' story and emerging lessons from supporting the UK response to the Ebola crisis. J R Army Med Corps 2016; 162(3): 169-75. DOI: 10.1136/jramc-2015-000512

[12] Herron JBT, Hay-David AGC, Gilliam AD, Brennan PA. Personal protective equipment and Covid 19- A risk to healthcare staff? Br J Oral Maxillofac Surg 2020; pii: S0266-4356(20)30165-0.

DOI: 10.1016/j.bjoms.2020.04.015

[13] Loh N-HW, Tan Y, Taculod J, et al. The impact of high-flow nasal cannula (HFNC) on coughing distance: Implications on its use during the novel coronavirus disease outbreak. Can J Anesth 2020; [Epub ahead of print]. DOI: 10.1007/s12630-020-01634-3

[14] an Doremalen N, Bushmaker T, Morris DH, et al. Aerosol and surface stability of SARS-CoV-2 as compared with SARS-CoV-1. New Engl J Med 2020; 382(16): 1564-7. DOI: 10.1056/NEJMc2004973 